\title{
UMA BREVE SÍNTESE DO CENÁRIO ATUAL DOS MEDICAMENTOS E TERAPIAS ANTIRRETROVIRAIS PARA O COMBATE AO HIV NO BRASIL
}

\section{A BRIEF OVERVIEW OF THE CURRENT SCENÁRIO ANTIRETROVIRAL DRUGS AND THERAPIES TO FIGHT HIV IN BRAZIL}

\author{
Robert Sousa de Araújo ${ }^{1}$, Bruno Leonardo do Nascimento-Dias ${ }^{2}$
}

\begin{abstract}
Submetido em: 12/03/2021
Aprovado em: 18/04/2021
\end{abstract}

\section{RESUMO}

HIV (sigla em inglês para Human Immunodeficiency Virus) teve sua primeira descrição no início da década de 80, sendo referido como um retrovírus capaz de transcrever seu genoma de ácido ribonucleico (RNA) em uma molécula de ácido desoxirribonucleico (DNA) de fita dupla, previamente à integração do genoma do vírus ao cromossomo da célula hospedeira. Nesse mesmo período, começou a ser desenvolvida a terapia antirretroviral (TARV), como meio de combater o avanço da doença em pacientes que possuíam o vírus. Dessa forma, o presente trabalho possui como objetivo principal apresentar os medicamentos e tratamentos oferecidos atualmente no Brasil para combater o HIV através das chamadas TARV. Para isto, a metodologia escolhida para o desenvolvimento desta pesquisa foi a de bibliográfica-descritiva. Os resultados coletados mostram que o Brasil conta com as seguintes classes de medicamentos como terapias antirretrovirais: Inibidores de protease (IP) Inibidores da transcriptase reversa análogos de nucleosídeo/Nucleotídeo (INTR/INTRt) Inibidores da transcriptase reversa não análogos de nucleosídeo (INNTR) Inibidores de entrada (IE) Inibidores de Integrase (INI). Além disso também será analisada as causas de falhas terapêuticas e como a utilização desses medicamentos em esquemas antirretrovirais está associada a melhora na qualidade de vida dos portadores de HIV.

PALAVRAS-CHAVES: Tarv. Hiv. Medicamentos.

\begin{abstract}
HIV (Human Immunodeficiency Virus) had its first description in the early 1980s, being referred to as a retrovirus capable of transcribing its ribonucleic acid (RNA) genome into a double-stranded deoxyribonucleic acid (DNA) molecule, prior to the integration of the virus genome into the host cell chromosome. In the same period, antiretroviral therapy (ART) began to be developed as a means of combating the progress of the disease in patients who had the virus. Thus, the present work has as main objective to present the drugs and treatments currently offered in Brazil to combat HIV through the so-called ART. For this, the methodology chosen for the development of this research was that of bibliographic-descriptive. The collected results show that Brazil has the following classes of drugs as antiretroviral therapies: Protease inhibitors (IP) Nucleoside / Nucleotide analog reverse transcriptase inhibitors (INTR / INTRt) Non-nucleoside analog reverse transcriptase inhibitors (INNTR) Inhibitors input (IE) Integrase Inhibitors (INI). In addition, the causes of therapeutic failures and how the use of these drugs in antiretroviral regimens is associated with an improvement in the quality of life of HIV patients will also be analyzed.
\end{abstract}

KEYWORDS: Tarv. Hiv. Medicine.

\footnotetext{
${ }^{1}$ Aluno de Licenciatura em Ciências Biológicas pelo Consórcio CEDERJ / UFRJ

2 Licenciatura em Física pela FTESM com graduação sanduíche em Bachelor of Science na Monash University em Melbourne na Austrália. Mestrado em Física pela UERJ e Doutorado em Física pela UFJF com ênfase em Astrobiologia
} 


\section{RECIMA21 - REVISTA CIENTÍFICA MULTIDISCIPLINAR ISSN 2675-6218}

UMA BREVE SÍNTESE DO CENÁRIO ATUAL DOS MEDICAMENTOS E TERAPIAS ANTIRRETROVIRAIS PARA O COMBATE AO HIV NO BRASIL Robert Sousa de Araújo, Bruno Leonardo do Nascimento-Dias

\section{INTRODUÇÃO}

O Vírus da Imunodeficiência Humana ou HIV (Human Immunodeficiency Virus) teve sua primeira descrição no início da década de 80, mais precisamente em Nova York, nos Estados Unidos da América. Foi encontrado em pacientes jovens, homossexuais masculinos que exibiam diversos sintomas complexos causados por Pneumocystis jiroveci (STRINGER et al., 2002) que normalmente se apresenta como um organismo eucariótico inofensivo, sarcoma de Kaposi que é uma forma extremamente rara de câncer, súbita perda de peso, linfadenopatia e supressão global da função do sistema imunológico. Esse conjunto de sinais e sintomas associados à doença, veio a ser conhecido como a síndrome de imunodeficiência adquirida ou AIDS (Acquired Immunodeficiency Syndrome) (STROHL et al., 2004).

O HIV pertence à família Retroviridae, subfamília Orthoretroviridae, gênero Lentivírus. Os retrovírus possuem a capacidade de transcrever seu genoma de RNA em uma molécula de ácido desoxirribonucleico (DNA) de fita dupla, previamente à integração do genoma do vírus ao cromossomo da célula hospedeira. Processo este que é mediado por uma DNA polimerase dependente de RNA, denominada Transcriptase Reversa (SUCCI, 1999).

Além disso, o vírus gera uma infecção latente de longo prazo nas células e efeitos citopáticos em curto prazo. Todos os Lentivírus são capazes de produzir doenças fatais de progressão lenta, incluindo síndromes que provocam o definhamento e degeneração do sistema nervoso central

O HIV é capaz de infectar células do sistema imunológico como macrófagos, células dendríticas e linfócitos TCD4+, promovendo sua destruição ou incapacitando-as, prejudicando assim o seu correto funcionamento no sistema imunológico. As células alvo do sistema imunológico funcionam como um reservatório que mantém a infecção viral por um longo período (GALLO, 1984).

Com o progresso da infecção pelo HIV, o sistema imunológico torna-se gradativamente inoperante e o indivíduo infectado, suscetível às infecções oportunistas, o que caracteriza o estágio mais avançado da infecção pelo HIV, que inclui também a baixa contagem de linfócitos TCD4+ tornando-se inferior a 200 células $/ \mathrm{mm}^{3}$, designando assim a Síndrome da Imunodeficiência Adquirida (SIDA) (BENNET et al., 2010). O tempo que decorre entre a infecção pelo HIV e o surgimento das primeiras infecções definidoras da AIDS pode levar de 10 a 15 anos.

O HIV pode ainda ser diferenciado em dois tipos antigênicos: HIV-1 e HIV-2, que apresentam nove e cinco subtipos, respectivamente. O HIV-1 possui distribuição global e é a causa mais frequente de AIDS enquanto que o HIV-2 limita-se na África Ocidental e também em algumas regiões da Europa (STEPHENS, 2012) e difere-se em sua estrutura genômica e antigenicidade e causa uma síndrome clinicamente semelhante. 


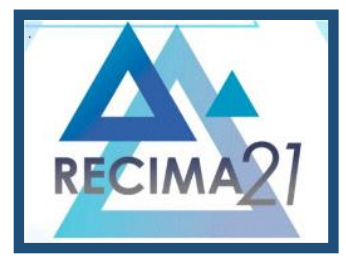

\section{RECIMA21 - REVISTA CIENTÍFICA MULTIDISCIPLINAR ISSN 2675-6218}

UMA BREVE SÍNTESE DO CENÁRIO ATUAL DOS MEDICAMENTOS E TERAPIAS ANTIRRETROVIRAIS PARA O COMBATE AO HIV NO BRASIL Robert Sousa de Araújo, Bruno Leonardo do Nascimento-Dias

Após a descoberta do agente etiológico causador da AIDS os avanços científicos mais expressivos têm ocorrido no desenvolvimento de fármacos antirretrovirais que retardam ou inibem a evolução do HIV no organismo, através do bloqueio de uma ou mais das etapas da replicação viral (DOMINGOS, 2006).

A terapia antirretroviral (TARV) teve seu início ainda na década de 1980, mais precisamente com a descoberta terapêutica do uso da Zidovudina (AZT) em 1986, que antes era um medicamento utilizado em doenças oncológicas. Vale salientar que houve uma progressiva melhora da qualidade de vida das pessoas portadoras do vírus HIV, que conforme LOPES (2007), este fármaco se caracteriza por ser um inibidor da transcriptase reversa análogo de nucleosídeo do HIV.

No Brasil, desde 1996, o SUS (Sistema Único de Saúde) fornece gratuitamente tratamento para as pessoas que vivem com HIV e disponibiliza também de forma gratuita os medicamentos necessários para a terapia antirretroviral, ofertando também a testagem gratuita, acompanhamento médico e genotipagem em casos de falha terapêutica (MELCHIOR et al, 2007).

Desde 2017 o protocolo terapêutico indica a terapia inicial com esquema preferencial de Inibidores de Transcriptase Reversa Análogo de Nucleosídeo/Nucleotídeo (ITRN/ITRNt) + Inibidores de Integrase (INI), sendo o Tenofovir Lamivudina + Dolutegravir adotados como esquema inicial (MS, 2017).

\section{METODOLOGIA}

Para isto, a metodologia escolhida para o desenvolvimento deste artigo é de uma pesquisa bibliográfica-descritiva. Conforme TRIVIÑOS (1987), uma pesquisa descritiva exige que o investigador busque informações sobre o que deseja pesquisar de forma a ser possível, com base nos dados coletados descrever o cenário ou panorama em análise de modo detalhado.

A pesquisa bibliográfica foi feita a partir do levantamento de referências teóricas já analisadas, e publicadas por meios escritos e eletrônicos, tais como boletins científicos, artigos e páginas do ministério da saúde do Brasil, portal de periódicos CAPES, sendo a pesquisa realizada no segundo semestre de 2020. De acordo com FONSECA (2002), uma pesquisa bibliográfica fornece informações importantes sobre o que já se estudou sobre o assunto, recolhendo conhecimentos prévios sobre o problema a respeito do qual procura-se desenvolver.

\section{RESULTADOS E DISCUSSÃO}

Atualmente no mundo todo existe um grande e crescente número de medicamentos antirretrovirais para o tratamento de pacientes infectados pelo HIV (KATZUNG, 2006). Todas as 


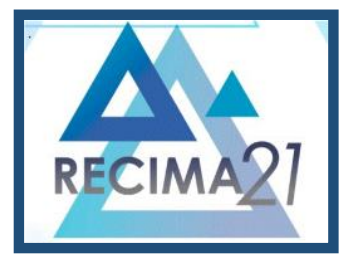

\section{RECIMA21 - REVISTA CIENTÍFICA MULTIDISCIPLINAR ISSN 2675-6218}

UMA BREVE SÍNTESE DO CENÁRIO ATUAL DOS MEDICAMENTOS E TERAPIAS ANTIRRETROVIRAIS PARA O COMBATE AO HIV NO BRASIL Robert Sousa de Araújo, Bruno Leonardo do Nascimento-Dias

etapas da replicação do HIV são alvos em potencial para uma droga antiviral (STROHL et al., 2004). A terapia antirretroviral conta com as seguintes classes de medicamentos:

- Inibidores de protease (IP)

- Inibidores da transcriptase reversa análogos de nucleosídeo/Nucleotídeo (INTR/INTRt)

- Inibidores da transcriptase reversa não análogos de nucleosídeo (INNTR)

- Inibidores de entrada (IE)

- Inibidores de Integrase (INI)

A não adesão ao tratamento, a toxicidade dos medicamentos e a resistência viral estão associados a falhas na terapia antirretroviral que por sua vez acarretam em piora no estado clínico do paciente (BRITO et al., 2006).

\section{CLASSES DE ANTIRRETROVIRAIS}

\section{Inibidores de Protease - IP}

Os inibidores da enzima viral protease surgiram como um avanço na terapia antirretroviral anti-HIV. A enzima protease é responsável pela clivagem das poliproteínas funcionais recémsintetizadas (produtos dos genes gag, p55 e gag-pol, p160) em proteínas estruturais e funcionais conhecidas como $p 7, p 9, p 17, p 24$, transcriptase reversa, integrase e a própria enzima protease. (SOUZA \& ALMEIDA, 2003).

Os inibidores de protease do HIV agem interferindo na última etapa da replicação viral, com a ausência desta clivagem crucial ocorre a produção de vírus imaturos que são incapazes de gerar novas infecções. A protease do HIV pertence à família das aspartil proteases, ou seja, possui dois grupos $\beta$-carboxi aspartil no sítio ativo. Substâncias químicas que mimetizam este intermediário tetraédrico impedem a hidrólise do substrato e, consequentemente, o ciclo do vírus HIV é interrompido (DORSEY et al, 2001).

A maioria dos fármacos licenciados pelo FDA possuem em sua estrutura uma ligação hidroxietileno ou uma ligação hidroxietilamina. O Saquinavir (SQV) foi o primeiro inibidor de protease licenciado, em 1995. Atualmente, esta classe de antirretrovirais conta com os seguintes medicamentos listados na Tabela 1:

Tabela 1: Lista de Inibidores de Protease - IP

\begin{tabular}{|c|}
\hline Inibidores de Protease - IP \\
\hline Atazanavir (ATV) \\
\hline Darunavir (DRV) \\
\hline
\end{tabular}




\section{RECIMA21 - REVISTA CIENTÍFICA MULTIDISCIPLINAR ISSN 2675-6218}

UMA BREVE SÍNTESE DO CENÁRIO ATUAL DOS MEDICAMENTOS E TERAPIAS ANTIRRETROVIRAIS PARA O COMBATE AO HIV NO BRASIL Robert Sousa de Araújo, Bruno Leonardo do Nascimento-Dias

\begin{tabular}{|c|}
\hline Fosamprenavir (FPV) \\
\hline Indinavir (IDV) \\
\hline Lopinavir (LPV) \\
\hline Nelfinavir (NFV) \\
\hline Ritonavir (RTV) \\
\hline Saquinavir (SQV) \\
\hline Tipranavir (TPV) \\
\hline Amprenavir (APV) \\
\hline
\end{tabular}

O maior efeito colateral relacionado ao uso desta classe de antirretrovirais é o surgimento de lipodistrofia (redistribuição de gordura, de modo que os membros se tornam magros e a gordura é depositada ao longo do abdômen e do dorso superior) e hiperglicemia (STROHL et al., 2004).

\section{É USADO NO BRASIL? QUAL PROTOCOLO TERAPEUTICO?}

\section{INIBIDORES DE INTEGRASE - INI}

A enzima integrase é a responsável pela incorporação do DNA viral ao cromossomo da célula do hospedeiro, atuando em reações altamente específicas e necessárias ao processo de integração permitindo assim a continuação do ciclo da replicação viral. Do ponto de vista mecanístico e estrutural a enzima integrase pertence a uma família diversificada de polinucleotídeo-transferases, que inclui enzimas como a $\mathrm{RNaseH}$ (que constitui um dos domínios da transcriptase reversa) e as transposases originadas de Tn5 (HARE et al, 2010). As transposases são enzimas que mediam o processo de transposição do DNA, onde estes fragmentos movimentam-se livremente pelo genoma. A enzima integrase possui 288 aminoácidos codificados pelo gene pol do HIV-1, sendo composta por três domínios funcionais: N-terminal, catalítico e C-terminal (NEAMATI, 2011).

A atuação da integrase pode ser dividida em três etapas: processamento do DNA viral por clivagem do nucleotídeo do terminal-3, formação do complexo de pré-integração e transferência de cadeia, quando o DNA viral é inserido no DNA da célula do hospedeiro (BLANCO \& MARTINEZ-PICADO, 2012). O primeiro medicamento desta classe foi o Raltegravir (RAL), aprovado em 2007 pela FDA. Esta classe de antirretrovirais conta com os seguintes medicamentos descritos na Tabela 2:

Tabela 2: Lista de Inibidores de Integrase - INI 


\section{RECIMA21 - REVISTA CIENTÍFICA MULTIDISCIPLINAR ISSN 2675-6218}

UMA BREVE SÍNTESE DO CENÁRIO ATUAL DOS MEDICAMENTOS E TERAPIAS ANTIRRETROVIRAIS PARA O COMBATE AO HIV NO BRASIL Robert Sousa de Araújo, Bruno Leonardo do Nascimento-Dias

\begin{tabular}{|c|}
\hline Inibidores de Integrase - INI \\
\hline Raltegravir (RAL) \\
\hline Dolutegravir (DTG) \\
\hline Elvitegravir (EVG) \\
\hline
\end{tabular}

Os efeitos adversos provocados por esses medicamentos são diarreia, náuseas, fadiga, dores de cabeça, e prurido (MS, 2008).

\section{INIBIDORES DE ENTRADA - IE}

A entrada na célula hospedeira é condição essencial para que o vírus estabeleça uma infecção produtiva, para isso todo vírus possui tropismo por determinado tipo celular, que varia de acordo com sua afinidade pelo receptor da célula-alvo (ABBAS et al., 2008). O vírus HIV infecta principalmente os linfócitos TCD4+, que são células de defesa que coordenam a resposta imune contra patógenos e também outras células que possuem em sua superfície o receptor CD4 como macrófagos e células dendríticas (CUNNINGHAM et al, 2010).

O vírus HIV une-se ao receptor CD4 através da glicoproteína gp120 que se encontra em sua superfície e se liga também aos co-receptores CCR5 e CXCR4 através da glicoproteína gp41 para completar a fusão. Os inibidores de entrada agem bloqueando a etapa de ligação entre o vírus HIV e os co-receptores CCR5 e CXCR4, impedindo que o material genético do vírus entre no interior da célula do hospedeiro e inibindo o ciclo viral (MS, 2008). Os medicamentos que atuam nesta classe de antirretrovirais estão na Tabela 3 a seguir:

Tabela 3: Lista de Inibidores de Entrada - IE

\begin{tabular}{|c|}
\hline Inibidores de Entrada - IE \\
\hline Enfurvitide (T-20) \\
\hline Maraviroc (MRV) \\
\hline Vicriviroc \\
\hline Aplaviroc \\
\hline
\end{tabular}

Entretanto, esta classe de antirretrovirais possui como efeitos colaterais dores de cabeça, dor e adormecimento nos pés e nas pernas, enjoo e insônia. 


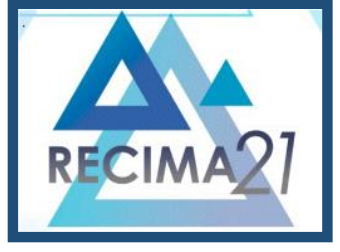

\section{RECIMA21 - REVISTA CIENTÍFICA MULTIDISCIPLINAR ISSN 2675-6218}

UMA BREVE SÍNTESE DO CENÁRIO ATUAL DOS MEDICAMENTOS E TERAPIAS ANTIRRETROVIRAIS PARA O COMBATE AO HIV NO BRASIL Robert Sousa de Araújo, Bruno Leonardo do Nascimento-Dias

\section{INIBIDORES DE TRANSCRIPTASE REVERSA ANÁLOGOS DE NUCLEOSÍDEO/NUCLEOTÍDEO - ITRN/ITRNT}

Uma vez ocorrida a fusão do envelope viral, alguns componentes internos do vírus são absorvidos e todo o processo de replicação viral no interior da célula se inicia, a enzima transcriptase reversa viral recodifica o RNA viral convertendo-o em DNA. Os inibidores de transcriptase reversa impedem a produção da cópia de DNA a partir do RNA, através da inibição competitiva do desoxinucleotideo trifosfato fisiológico, impedindo, assim, a extensão da fita de DNA (MANENTI, 2008).

Para que tenham atividade antiviral contra a enzima transcriptase reversa, os inibidores necessitam serem fosforilados pelo organismo pelas enzimas celulares chamadas de quinases, onde o metabólito, trifosfato, interrompe, de forma competitiva, a replicação viral impedindo sua formação (FDA, 2011).

O primeiro medicamento desta classe de antirretroviral foi a Zidovudina (AZT), sendo aprovado pelo FDA em 1987 (FDA, 2011). Dentre os medicamentos disponíveis para esta classe de antirretrovirais pode-se listar na seguinte Tabela 4:

Tabela 4: Lista de Inibidores de Transcriptase Reversa Análogos de Nucleosídeo/Nucleotídeo - ITRN/ITRNt

\begin{tabular}{|c|}
\hline Inibidores de Transcriptase Reversa Análogos de Nucleosídeo/Nucleotídeo - ITRN/ITRNt \\
\hline Lamivudina (3TC) \\
\hline Abacavir (ABC) \\
\hline Zidovudina (AZT) \\
\hline Estavudina (d4T) \\
\hline Didanosina (ddl) \\
\hline Emtricitabina (FTC) \\
\hline Tenofovir (TDF) \\
\hline
\end{tabular}

Os efeitos colaterais mais comuns decorrentes desta classe de antirretrovirais são anemia macrocítica, neutropenia e granulocitopenia, intolerância gastrointestinal, cefaleia, vertigem, insônia, perda momentânea da memória, inflamação hepática e miosite (MS, 2008).

\section{INIBIDORES DE TRANSCRIPTASE REVERSA NÃO ANÁLOGOS DE NUCLEOSÍDEO - ITRNN}

Este tipo de medicamento se baseia no mecanismo de bloqueio direto da enzima transcriptase reversa, através de sua interação com um sítio de ligação alostérico localizado a 


\section{RECIMA21 - REVISTA CIENTÍFICA MULTIDISCIPLINAR ISSN 2675-6218}

UMA BREVE SÍNTESE DO CENÁRIO ATUAL DOS MEDICAMENTOS E TERAPIAS ANTIRRETROVIRAIS PARA O COMBATE AO HIV NO BRASIL Robert Sousa de Araújo, Bruno Leonardo do Nascimento-Dias

aproximadamente 10 nanômetros de distância do sítio catalítico da enzima, o que promove mudanças conformacionais levando a sua inativação (TANTILLO, 1994). O primeiro medicamento desta classe liberado para uso foi a Nevirapina (NVP), aprovada em 1996, atualmente esta classe conta com os medicamentos da Tabela 5:

Tabela 5: Lista de Inibidores de Transcriptase Reversa Não Análogos de Nucleosídeo ITRNN

\begin{tabular}{|c|}
\hline Inibidores de Transcriptase Reversa Não Análogos de Nucleosídeo - ITRNN \\
\hline Nevirapina (NVP) \\
\hline Delavirdina (DLV) \\
\hline Efavirenz (EFV) \\
\hline Etravirina (ETR) \\
\hline
\end{tabular}

Os efeitos colaterais associados são hepatotoxicidade, reação cutânea grave, cefaleia, neuropatia periférica e fadiga.

\section{QUANDO E COMO INICIAR}

Segundo a WHO (2013), recomenda-se que os programas nacionais de HIV forneçam terapia antirretroviral para as pessoas com diagnóstico confirmado de HIV com uma contagem de CD4 de 500 células/mm3 ou menos, dando prioridade para iniciar a terapia entre aqueles com doença grave HIV / avançado ou uma contagem de CD4 de 350 células $/ \mathrm{mm} 3$ ou menos. Também é recomendado para pessoas com tuberculose ativa e coinfecção pelo vírus da hepatite $\mathrm{B}$ com doença hepática grave, mulheres grávidas e lactantes com HIV, crianças menores de cinco anos que vivem com HIV e indivíduos com HIV em relacionamentos sorodiscordantes, independentemente da contagem de células CD4.

Tabela 6 - Indicações de esquemas para TARV

\begin{tabular}{|c|c|}
\hline SITUAÇÃO & RECOMENDAÇÃOO \\
\hline PVHIV sintomática & \multirow{7}{*}{$\begin{array}{l}\text { Priorização de acesso ao atendimento pelos serviços da rede de } \\
\text { assistência à PVHIV } \\
\text { Iniciar TARV com celeridade }\end{array}$} \\
\hline LT-CD4+ «350 céls/ın! & \\
\hline Gestante & \\
\hline Tuberculose ativa & \\
\hline Coinfecção HBV & \\
\hline Coinfecção HCV & \\
\hline $\begin{array}{l}\text { Risco cardiovascular elevado } \\
(>20 \%)\end{array}$ & \\
\hline
\end{tabular}

Fonte: DIAHV/SVS/MS.

ISSN: 2675-6218 - RECIMA21 - Ciências Exatas e da Terra, Sociais, da Saúde, Humanas e Engenharia/Tecnologia 


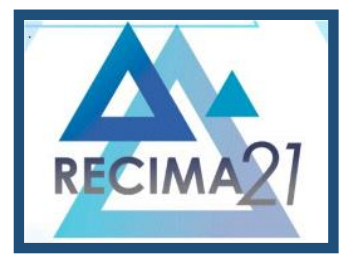

\section{RECIMA21 - REVISTA CIENTÍFICA MULTIDISCIPLINAR ISSN 2675-6218}

UMA BREVE SÍNTESE DO CENÁRIO ATUAL DOS MEDICAMENTOS E TERAPIAS ANTIRRETROVIRAIS PARA O COMBATE AO HIV NO BRASIL Robert Sousa de Araújo, Bruno Leonardo do Nascimento-Dias

No Brasil, o consenso indica o início da TARV para todos os indivíduos sintomáticos, independentemente da contagem de LT-CD4+ e para as pessoas vivendo com HIV/AIDS (PVHA) com tuberculose ativa, independentemente da forma clínica e contagem de LT-CD4+. Para os indivíduos assintomáticos com LT-CD4+ menor ou igual a 500 células/mm3 e LT-CD4+ acima de 500 células/mm3 na coinfecção pelo vírus da hepatite B (HBV) (BRASIL, 2013c). O início do TARV deve ser considerado também nas seguintes situações: LT-CD4+ acima de 500 células/mm3 associada à doença cardiovascular estabelecida ou risco cardiovascular elevado (acima de 20\%, segundo escore de Framingham), neoplasias não definidoras de AIDS com indicação de quimioterapia ou radioterapia, coinfecção pelo vírus da hepatite $\mathrm{C}(\mathrm{HCV})$ e carga viral acima de 100.000 cópias/mL (BRASIL, 2013c).

Evidências recentes indicam que, o uso de terapia antirretroviral precocemente auxilia as pessoas com HIV a terem vidas mais longas e saudáveis e reduz substancialmente o risco de transmissão do HIV para outras pessoas. Esta medida pode evitar um adicional de 3 milhões de mortes e prevenir mais de 3,5 milhões de novas infecções pelo HIV até 2025 (HIRNSCHALL et al., 2013; WHO, 2013).

Segundo FERNANDES et al. (2009), o início tardio da TARV pode ser prejudicial ao estado do paciente. Seu início precoce permite que, quanto mais pessoas infectadas estiverem em tratamento, menor será a ocorrência de novas infecções. Vários países, inclusive o Brasil, já vêm adotando esta prática. Assim, o início do tratamento precoce está associado com benefícios clínicos e de prevenção do HIV, melhorando a sobrevida e reduzindo a incidência de infecção pelo HIV (WHO, 2013b).

Para BARLETT e GALLANT (2004) o principal objetivo clínico que se almeja atingir com a utilização da TARV é o prolongamento e melhora da qualidade de vida dos pacientes; o objetivo virológico é a redução da carga viral (>20 a 50 cópias $/ \mathrm{mL}$ ) para evitar ou retardar a progressão da doença; e o imunológico inclui a reconstituição imunológica quantitativamente e qualitativamente. Por fim, o objetivo terapêutico a ser alcançado é o uso racional dos medicamentos para atingir o objetivo clínico, preservando as opções terapêuticas, limitando os efeitos tóxicos e facilitando a adesão.

Com isso, alcança-se o objetivo epidemiológico que trata da redução da transmissão do vírus HIV. ANGLEMYER et al. (2013), verificaram em seu estudo que tratamentos antirretrovirais podem prevenir a transmissão do HIV de um parceiro sexual infectado para um não infectado, por suprimir a replicação viral.

Os mesmos autores observaram que entre casais em que um dos parceiros era soro positivo mas estava em uso de TARV, houve uma diminuição de $40 \%$ do risco de infecção do 


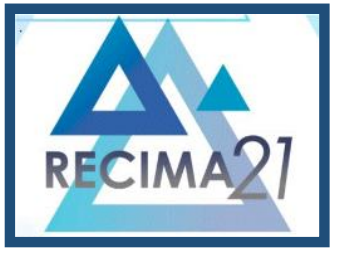

\section{RECIMA21 - REVISTA CIENTÍFICA MULTIDISCIPLINAR ISSN 2675-6218}

UMA BREVE SÍNTESE DO CENÁRIO ATUAL DOS MEDICAMENTOS E TERAPIAS ANTIRRETROVIRAIS PARA O COMBATE AO HIV NO BRASIL Robert Sousa de Araújo, Bruno Leonardo do Nascimento-Dias

outro parceiro ao se comparar com casais onde o parceiro infectado não estava recebendo tratamento. Nesta perspectiva, medicamentos cada vez mais potentes e seletivos vêm sendo introduzidos ao consenso. No entanto, a fim de potencializar a efetividade do tratamento, devemse considerar também as diferenças fisiológicas entre os indivíduos que podem causar alterações quantitativas nos níveis plasmáticos dos antirretrovirais, gerando variação de eficácia entre os diferentes esquemas terapêuticos (BONOLO, 2007).

No consenso terapêutico (BRASIL, 2013c) indica-se a terapia inicial com esquema preferencial de Inibidores da Transcriptase Reversa Análogo de Nucleosídeo/Nucleotídeo (ITRN/ITRNt) + Inibidores de Integrase (INI), como regra, o esquema de primeira linha deve ser tal como na Tabela 7.

Tabela 7 - Esquema inicial preferencial

\section{Esquema de terapia inicial - primeira linha}

\section{TDF + 3TC + DTG}

\begin{tabular}{|c|c|c|c|}
\hline SITUAÇÃO & $\begin{array}{c}\text { TERAPIA } \\
\text { ANTIRRETROVIRAL }\end{array}$ & DOSE DIÁRIA & OBSERVAÇĀO \\
\hline $\begin{array}{l}\text { Adultos em inicio } \\
\text { de tratamento }\end{array}$ & $\mathrm{TDF}^{(\mathrm{t})} / 3 \mathrm{TC}+\mathrm{DTG}^{(\mathrm{c})}$ & $\begin{array}{c}(300 \mathrm{mg} / 300 \mathrm{mg}) " 2 \times 1 "+ \\
50 \mathrm{mg} \\
1 \mathrm{x} / \mathrm{dia}\end{array}$ & \\
\hline $\begin{array}{l}\text { Coinfecção TB-HIV } \\
\text { sem critérios de } \\
\text { gravidade (conforme } \\
\text { critérios elencados } \\
\text { abaixo) }\end{array}$ & $\mathrm{TDF}^{(\mathrm{b})} / 3 \mathrm{TC} / \mathrm{EFV}$ & $\begin{array}{c}(300 \mathrm{mg} / 300 \mathrm{mg} / 600 \mathrm{mg}) \\
-\mathrm{DFC} \\
1 \mathrm{x} / \mathrm{dia}\end{array}$ & $\begin{array}{l}\text { Concluido o tratamento } \\
\text { completo para TB, } \\
\text { poderá ser feita a } \\
\text { mudança (switch) do } \\
\text { EFV para DTG. }\end{array}$ \\
\hline $\begin{array}{l}\text { Coinfecção TB-HIV com } \\
\text { um ou mais dos critérios } \\
\text { de gravidade abaixo }{ }^{(d):} \\
\text { LT-CD4+ } 100 \text { céls/mm } \\
\text { Presença de outra } \\
\text { infecçâo oportunista } \\
\text { Necessidade de } \\
\text { internação hospitalar/ } \\
\text { doença grave } \\
\text { Tuberculose disseminada }\end{array}$ & $\mathrm{TDF}^{(\mathrm{b})} / 3 \mathrm{TC}+\mathrm{RAL}$ & $\begin{array}{c}(300 \mathrm{mg} / 300 \mathrm{mg}) " 2 \times 1 " \\
1 \mathrm{x} / \mathrm{dia} \\
+ \\
400 \mathrm{mg} \\
12 / 12 \mathrm{~h}\end{array}$ & $\begin{array}{l}\text { Concluido o } \\
\text { tratamento completo } \\
\text { de TB, deverá ser feita } \\
\text { a mudança (switch) do } \\
\text { RAL para DTG em até } 3 \\
\text { meses }\end{array}$ \\
\hline
\end{tabular}

Fonte: DIAHV/SVS/MS.

Exceção a esse esquema deve ser observada para os casos de coinfecção TB-HIV, MVHIV com possibilidade de engravidar e gestantes. Situações especiais de intolerância ou contraindicação devem ter seus esquemas iniciais adequados para esquemas iniciais alternativos, conforme a Tabela 8 a seguir: Tabela 8 - Posologia indicada para TARV 

ISSN 2675-6218

\section{FALHA TERAPÊUTICA E TERAPIA DE RESGATE}

No que se diz respeito ao TARV, na última década, houve um aumento progressivo nas taxas de respostas terapêuticas com os antirretrovirais modernos ao menos $80 \%$ dos pacientes obtiveram uma carga viral inferior a 50 cópias $/ \mathrm{mL}$ após um ano (MS, 2018). O principal parâmetro que caracteriza a falha da TARV é a falha virológica, isto é, carga viral de HIV detectável após seis meses do início ou da modificação do tratamento, ou rebote da carga viral de HIV em indivíduos que haviam atingido supressão viral sob tratamento.

A falha virológica prejudica a recuperação imunológica, aumenta o risco de progressão da doença e leva à emergência de cepas resistentes ao TARV. A supressão parcial e a persistência de carga viral de HIV detectável, mesmo em níveis baixos, levam ao acúmulo de mutações que conferem resistência não só aos medicamentos em uso, mas também a outros da mesma classe, o que, consequentemente, resulta em perda de opções terapêuticas (MS, 2018).

A principal causa de falha da TARV é a má adesão do paciente ao tratamento. Fatores psicossociais, como depressão, uso de substâncias psicoativas, dificuldade de acesso e comorbidades, além de fatores relacionados aos medicamentos, como efeitos adversos e posologia complexa, contribuem para a má adesão.

Durante os períodos de adesão irregular, níveis séricos baixos dos medicamentos, insuficientes para suprimir completamente a replicação viral, exercem pressão seletiva sobre a população viral e promovem a emergência de subpopulações resistentes aos medicamentos.

A resistência viral adquirida, consequência imediata da má adesão, passa a ser causa da falha virológica. De fato, mutações de resistência ao TARV são detectadas em até $90 \%$ dos casos de falha virológica (MS, 2018). A transmissão de vírus resistentes (resistência transmitida) é a causa menos comum de falha virológica (HERNANDEZ et al., 2017), entretanto, na última década, um aumento progressivo da taxa de resistência transmitida aos ITRNN tem sido documentado. Os INI como base do esquema de tratamento inicial contornam a questão da resistência transmitida, já que a transmissão de vírus com mutações de resistência no gene da integrase continua a ser rara (HERNANDEZ et al., 2017).

Esquemas inadequados, seja pela potência insuficiente, seja pela baixa barreira genética (terapia dupla, terapia tripla com três ITRN, monoterapia com IP/r, IP sem potencialização pelo ritonavir), seja por interações medicamentosas, são associados a maior risco de falha da TARV. Comorbidades resultando em vômitos ou diarreia podem impedir a absorção adequada dos medicamentos e contribuir para a falha do tratamento (MS, 2017).

Dessa forma, indica-se o exame de genotipagem para o HIV disponível no SUS na Rede Nacional de Genotipagem (Renageno). Os critérios para realização do teste de genotipagem pelo Renageno são (MS, 2017): 


\section{RECIMA21 - REVISTA CIENTÍFICA MULTIDISCIPLINAR ISSN 2675-6218}

UMA BREVE SÍNTESE DO CENÁRIO ATUAL DOS MEDICAMENTOS E TERAPIAS ANTIRRETROVIRAIS PARA O COMBATE AO HIV NO BRASIL Robert Sousa de Araújo, Bruno Leonardo do Nascimento-Dias

- Falha virológica confirmada em dois exames consecutivos de carga viral de HIV, com intervalo de quatro semanas entre eles;

- Carga viral de HIV superior a 500 cópias $/ \mathrm{mL}$;

- Uso regular de TARV por pelo menos seis meses.

Uma vez detectada e confirmada a falha virológica, recomenda-se a pesquisa de resistência viral ao TARV, cujo resultado auxilia na elaboração de um esquema de resgate com maior chance de supressão viral. Entre suas principais vantagens, destacam-se (MS, 2008):

- Possibilita escolha de esquemas antirretrovirais com maior chance de supressão viral, com base na identificação de mutações de resistência;

- Propicia o uso de medicamentos ativos por períodos mais prolongados;

- Previne trocas desnecessárias de ARV;

- Previne toxicidade de medicamentos inativos;

- Melhora a relação de custo-efetividade do tratamento.

\section{CONSIDERAÇÕES FINAIS}

Como descrito no presente trabalho, há disponível no mercado brasileiro uma ampla gama de medicamentos antirretrovirais contra o HIV/AIDS que atuam nas diferentes etapas de replicação viral. Cada medicamento possui sua particularidade, tanto em eficácia como em efeitos colaterais diversos. Apesar da forte aplicabilidade da terapia antirretroviral, que conta com a combinação de, no geral, menos de 3 classes diferentes de medicamentos disponíveis no Brasil através do SUS, ainda em alguns casos, pode haver a ocorrência de falha na terapia, com aumento da carga virológica. Esse acontecimento se deve as mais diversas causas como má adesão aos medicamentos, abandono da terapia e resistência viral. Entretanto, não há dúvidas que a descoberta e o desenvolvimento dos medicamentos antirretrovirais trouxeram uma melhora na perspectiva e qualidade de vida das pessoas portadoras do vírus HIV.

\section{REFERÊNCIAS}

ABBAS, A. K.; LICHTMAN, A. H.; POBER, J. S. Imunologia celular e molecular. 6. ed Rio de Janeiro: Elsevier, 2008.

ANGLEMYER, A.; RUTHERFORD, G. W.; HORVATH, T. et al. Antiretroviral therapy for prevention of HIV transmission in HIV-discordant couples. Cochrane Database of Systematic Reviews, v. 4, n. CD009153, 2013. DOI: 10.1002/14651858.CD009153.pub3. Acesso em: 11 mar. 2021.

BARLETT, J.; GALLANT, J. Medical Management of HIV Infection. Baltimore-Maryland: Johns Hopkins, 2004. 


\section{RECIMA21 - REVISTA CIENTÍFICA MULTIDISCIPLINAR ISSN 2675-6218}

UMA BREVE SÍNTESE DO CENÁRIO ATUAL DOS MEDICAMENTOS E TERAPIAS ANTIRRETROVIRAIS PARA O COMBATE AO HIV NO BRASIL Robert Sousa de Araújo, Bruno Leonardo do Nascimento-Dias

BENNETT, D. E.; MYATT, M.; BERTAGNOLIO, S. et al. Recommendations for surveillance of transmitted HIV drug resistance in countries scaling up antiretroviral treatment. Antivir Ther, v. 13, Suppl 2, p. 25-36, 2008.

BLANCO, J. L.; MARTINEZ-PICADO, J. (2012). HIV integrase inhibitors in ART-experienced patients. Current Opinion in HIV and AIDS, v. 7, n. 5, p. 415-421, 2012.

BONOLO, P. F.; GOMES, R. R.; GUIMARÃES, M. D. C. Adesão à terapia anti-retroviral (HIV/aids): fatores associados e medidas de adesão. Epidemiol. Serv. Saúde, v. 16, n. 4, p. 261-78, 2007. Disponível em: http://scielo.iec.pa.gov.br/scielo.php?script=sci pdf\&pid=S167949742007000400005\&lng=pt\&nrm =iso\&tlng=pt. Acesso em: 05 jul. 2020.

BRASIL. Ministério da Saúde. Agência Nacional de Vigilância Sanitária (ANVISA). Assistência segura: uma reflexão teórica aplicada à prática - Série Segurança do Paciente e Qualidade em Serviços de Saúde/Agência Nacional de Vigilância Sanitária. Brasília: ANVISA, 2013c. Disponível em: https://www20.anvisa.gov.br/segurancadopaciente/index.php/publicacoes/item/caderno-1assistencia-segura-uma-reflexao-teorica-aplicada-a-pratica. Acesso em: 05 jul. 2020.

BRASIL. Ministério da Saúde. Secretaria de Vigilância em Saúde. Programa Nacional de DST e Aids. Manual de adesão ao tratamento para pessoas vivendo com HIV e Aids. Brasília: Ministério da Saúde, 2008.

BRASIL. Ministério da Saúde (MS). Departamento Nacional de DST/AIDS e Hepatites Virais. Boletim Epidemiológico- AIDS e DST. Brasília: Departamento Nacional de DST/Aids e Hepatites Virais, 2017.

BRASIL. Ministério da Saúde. Departamento de Vigilância. Prevenção e Controle das Infecções Sexualmente Transmissíveis, do HIV/Aids e das Hepatites Virais. Protocolo Clínico e Diretrizes Terapêuticas para Manejo da Infecção pelo HIV em adultos. Brasília: Ministério da Saúde, 2018. $412 \mathrm{p}$.

BRITO, Ana Maria de; SZWARCHALD, Célia Landmann; CASTILHO, Euclides Ayres de. Fatores associados à interrupção de tratamento anti-retroviral em adultos com AIDS. Rio Grande do Norte, Brasil, 1999-2002. Rev Assoc Méd Brás, Rio Grande do Norte, v. 52, n. 2, p. 86-92, 2006.

CUNNINGHAM, A. L.; DONAGHY, H.; HARMAN, A. N. et. al. Manipulation of dendritic cell function by viruses. Curr Opin Microbiol, v. 13, n. 4, p. 524-9, Aug. 2010.

DOMINGOS, Hamilton. Efeitos Metabólicos Associados à Terapia Anti-retroviral Potente em Pacientes com AIDS. 2006. 103 f. Dissertação (Mestrado em Ciências da Saúde) - Convenio Rede Centro-Oeste UnB/UFG/UFMS, Campo Grande, 2006.

DORSEY B. D.; VACCA, J. P. Em Protease Inhibitors in AIDS Therapy. New York: Marcel Dekker Inc, 2001. Cap. 4. 


\section{RECIMA21 - REVISTA CIENTÍFICA MULTIDISCIPLINAR ISSN 2675-6218}

UMA BREVE SÍNTESE DO CENÁRIO ATUAL DOS MEDICAMENTOS E TERAPIAS ANTIRRETROVIRAIS PARA O COMBATE AO HIV NO BRASIL Robert Sousa de Araújo, Bruno Leonardo do Nascimento-Dias

FERNANDES, J. R. M. et al. Início da terapia anti-retroviral em estágio avançado de imunodeficiência entre indivíduos portadores de HIV/AIDS em Belo Horizonte, Minas Gerais, Brasil. Caderno Saúde Pública, Rio de Janeiro, v. 25, n. 6, p. 1369-1380, jun. 2009.

FONSECA, J. J. S. Metodologia da pesquisa científica. Fortaleza: UEC, 2002.

GALLO, R. C. Kaplan memorial lecture. The family of human lymphotropic retro-viruses called HTLV: HTLV-I in adult T-cell leukemia (ATL), HTLV-II in hairy cell leukemias, and HTLV-III in AIDS. Princess Takamatsu Symp, v. 15, p. 13-38, 1984.

HARE, S.; GUPTA, S. S.; VALKOV, E. et al. Retroviral intasome assembly and inhibition of DNA strand transfer. Nature, v. 464, p. 232-6, 2010.

HERNANDEZ, A. L. et al. HIV Integrase Genotypic Testing and Resistance in the United States-9 U.S. Jurisdictions. São Francisco-CA: CROI, 2017.

HIRSCHALL, G.; DOHERTY, M.; FORD, N. et al. The 2013 WHO guidelines for antiretroviral therapy: evidence-based recommendations to face new epidemic realities. Curr Opin HIV AIDS, v. 8, n. 6, p. 528-34, nov. 2013.

KATZUNG, Bertram G. Farmacologia: básica \& clínica. 9. ed. Rio de Janeiro: Guanabara Koogan, 2006. p. 677.

LOPES, Antonio Carlos. Diagnóstico e tratamento. São Paulo: Manole, 2007. v. 3.

MANENTI, Sandra Aparecida. Epidemiologia e Caracterização Molecular do HIV-1 em Gestantes do Sul de Santa Catarina do Período de Janeiro a Dezembro de 2007. 2008. 136 f. Dissertação (Mestrado em Ciências da Saúde) - Universidade do Extremo Sul Catarinense, Criciúma, 2008.

MELCHIOR, R. et al. Desafios da adesão ao tratamento de pessoas Vivendo com HIV/Aids no Brasil. Rev Saúde Pública, v. 41, n, 2, p. 87-93, 2007

MINISTÉRIO DA SAÚDE. Secretaria de Vigilância em Saúde - Programa Nacional de DST e AIDS. 7. ed Brasília: Ministério da Saúde, 2008.

NEAMATI, N. HIV-1 integrase: mechanism and inhibitor design. New Jersey: John Wiley \& Sons, 2011.

OJEWOLE, E. et al. Exploring the use of novel drug delivery systems for antiretroviral drugs. European Journal of Pharmaceutics and Biopharmaceutics, v. 70, p 697-710, 2008.

SOUZA, Marcus Vinícius Nora de, ALMEIDA, Mauro Vieira de. Drogas Anti-VHI: Passado, Presente e perspectivas futuras. Quim. Nova, Rio de Janeiro, v. 26, n. 3, p. 366-372, maio/jun. 2003.

STEPHENS, H. A. Immunogenetic surveillance of HIV/AIDS. Infect Genet Evol, v. 12, n. 7, p. 1481-91, Oct. 2012. 


\section{RECIMA21 - REVISTA CIENTÍFICA MULTIDISCIPLINAR ISSN 2675-6218}

UMA BREVE SÍNTESE DO CENÁRIO ATUAL DOS MEDICAMENTOS E TERAPIAS ANTIRRETROVIRAIS PARA O COMBATE AO HIV NO BRASIL Robert Sousa de Araújo, Bruno Leonardo do Nascimento-Dias

STRINGER, James R.; BEARD, Charles B.; MILLER, Robert F.; WAKEFIELS, Ann E. A New Name (Pneumocystis jiroveci) for Pneumocystis from Humans. Emerging Infectious Diseases, Atlanta, v. 8, n. 9, p.891-896, sep. 2002.

STROHL, William A.; ROUSE, Harriet; FISHER, Bruce D. Microbiologia ilustrada. Porto Alegre: Artmed, 2004. p. 374-376, 378 e 387-389.

SUCCI, R. C. Síndrome da imunodeficiência adquirida. In.: FARHAT, C. K.; CARVALHO, E. S.; CARVALHO, L. H. F. R.; SUCCI, R. C. M. Infectologia pediátrica. São Paulo: Atheneu, 1999. p. 488-495.

TANTILLO, C.; DING, J. JACOBO-MOLINA, A. et al. Locations of anti-AIDS drug binding sites and resistance mutations in the three-dimensional structure of HIV-1 reverse transcriptase. J. Mol. Biol, v. 243, p. 369-387, 1994.

TRIVIÑOS, Augusto N. S. Introdução à pesquisa em ciências sociais: a pesquisa qualitativa em educação. São Paulo: Atlas, 1987.

WORLD HEALTH ORGANIZATION. Disponível em: http://www.who.int/topics/hiv aids/en/. Acesso em: 20 jun. 2013. 